\title{
Atividade biológica de solo sob cultivo múltiplo de maracujá, abacaxi, milho, mandioca e plantas de cobertura ${ }^{1}$
}

\author{
Soil biological activity under intercropping of passion fruit, pineapple, maize, cassava \\ and cover crops
}

\author{
Sebastião Elviro de Araújo Neto ${ }^{2 *}$, Alisson Nunes da Silva ${ }^{3}$, Jorge Ferreira Kusdra ${ }^{2}$, Faelen Tais Kolln ${ }^{3}$ e Romeu \\ de Carvalho Andrade Neto ${ }^{4}$
}

\begin{abstract}
RESUMO - O objetivo deste trabalho foi avaliar o efeito de plantas de cobertura em cultivo consorciado de maracujá, abacaxi, mandioca e milho sobre a atividade biológica do solo em período chuvoso e de estiagem. O experimento foi conduzido em Rio Branco, Acre, em um ARGISSOLO AMARELO Alítico plíntico. O delineamento experimental utilizado foi o de blocos casualizados completos com parcelas subdivididas e quatro repetições. Nas parcelas foram estudadas épocas de avaliação (março, maio, agosto e outubro de 2011) e, nas subparcelas, plantas de cobertura [kudzu tropical (Pueraria phaseoloides), crotalaria (Crotalaria espectabilis), amendoim forrageiro (Arachis pintoi), feijão de porco (Canavalia ensiformis) e plantas espontâneas]. Foram avaliadas respiração (edáfica e basal), biomassa microbiana, e quocientes metabólico $\left(\mathrm{qCO}_{2}\right)$ e microbiano (qMIC). No final do período chuvoso, em condições de adequada umidade e oxigenação do solo, a cobertura com crotalária potencializa a atividade microbiana juntamente com e feijão de porco, que proporciona maior respiração edáfica. No período com maior restrição do oxigênio no solo (outubro a março - estação chuvosa) e de água (agosto - característico da estação seca), o amendoim forrageiro mantém alta atividade microbiana. No período de maior precipitação pluviométrica (março), o solo sob plantas espontâneas apresenta maiores biomassa microbiana e eficiência metabólica.
\end{abstract}

Palavras-chave: Cultivo consorciado. Emissão de $\mathrm{CO}_{2}$. Dinâmica do carbono.

\begin{abstract}
The objective of this work was to evaluate the effect of cover crops on the biological activity of the soil in the rainy and dry seasons, under the intercropping of passion fruit, pineapple, cassava and maize. The experiment was carried out in Rio Branco, in the state of Acre in Brazil, in a plinthic allitic Yellow Argisol. The experimental design used was of complete randomised blocks with split lots and four replications: with the evaluation periods for the lots (March, May, August and October of 2011) and the cover crops for the sublots [tropical kudzu (Pueraria phaseoloides), crotalaria (Crotalaria spectabilis), pinto peanut (Arachis pintoi), jack bean (Canavalia ensiformis) and weeds]. The following were evaluated: respiration (edaphic and basal), microbial biomass, and metabolic (qCO2) and microbial (qMIC) quotients. At the end of the rainy season, under adequate conditions of moisture and oxygenation in the soil, crotalaria cover enhances microbial activity together with the jack bean, which provides better edaphic respiration. During the period when soil oxygen is more restricted (from October to March - the rainy season) and water (August characteristic of the dry season), the pinto peanut helps maintain high microbial activity. In the period of greatest rainfall (March), the soil under weed cover displays greater microbial biomass and metabolic efficiency.
\end{abstract}

Key words: Intercropping. $\mathrm{CO}_{2}$ emission. Carbon dynamics.

\footnotetext{
*Autor correspondência

${ }^{1}$ Recebido publicação em 01/04/2013; aprovado em 19/05/2014

Trabalho realizado como parte da Dissertação do segundo autor do Programa de Pós-Graduação em Produção Vegetal da UFAC com financiamento de bolsas CAPES e CNPq concedida aos autores

${ }^{2}$ Centro de Ciências Biológicas e da Natureza, Universidade Federal do Acre, Rio Branco-AC, Brasil, selviro2000@yahoo.com.br; kusdra@globo.com ${ }^{3}$ Programa de Pós-Graduação em Produção Vegetal, Universidade Federal do Acre, Rio Branco-AC, Brasil, floydwatters@ hotmail.com; fkolln@gmail.com

${ }^{4}$ Empresa Brasileira de Pesquisa Agropecuária, Rio Branco-AC, Brasil, romeu.andrade@embrapa.br
} 


\section{INTRODUÇÃO}

A exploração dos solos na Amazônia foi realizada por décadas de forma extrativista sem significativos impactos ambientais. Entretanto, posteriormente, para integrar a região ao processo produtivo e econômico do país sistemas agrícolas e, principalmente, pastoris, passaram a tornar-se cada vez mais frequentes, vinculando-se a estes práticas insustentáveis como derrubada e queima da vegetação natural (CASTRO et al., 2008).

As práticas agrícolas podem contribuir para prejudicar, manter ou melhorar os indicadores de qualidade edáfica. $\mathrm{O}$ uso de agrotóxicos, por exemplo, tende a comprometer o equilíbrio biológico do solo causando extinção de espécies e perda de diversidade (PRIETO-BENÍTEZ; MÉNDEZ, 2011). Por outro lado, a adição de matéria orgânica, a cobertura morta e a adubação verde normalmente interferem positivamente em várias características físicas, químicas e biológicas do solo (GARCÍA-ORENES et al., 2010). Além disso, se o sistema de cultivo for orgânico há maior micorrização e atividade microbiana do solo (FREITAS et al., 2011).

A presença na área de cultivo de diferentes espécies vegetais aumenta a diversidade de substrato (biomassa), seja com plantas cultivadas ou de cobertura (adubo verde), que é fundamental para a manutenção da diversidade biológica do solo (HUNGRIA et al., 2009; LORANGERMERCIRISA et al., 2006; XUE-MEI et al., 2007).

Entre as características consideradas desejáveis na escolha da espécie de planta para cobertura do solo incluem-se alta produtividade de biomassa de parte aérea e de raiz (ESPINDOLA et al., 2006), capacidade de rápida mineralização e ciclagem de nutrientes (DUDA et al., 2003), redução da infestação de plantas daninhas (SILVA; HIRATA; MONQUERO, 2009), promoção de agregação de partículas e atenuação de oscilações térmicas e hídricas do solo (LOSS et al., 2009) e controle de pragas agrícolas (BEZERRA et al., 2004; SAKONNAKHON et al., 2006).

A liberação de $\mathrm{C}_{-} \mathrm{CO}_{2}$ pelos microrganismos (respiração basal) e por estes junto a invertebrados e raízes de plantas (respiração edáfica) são os principais indicadores da atividade biológica do solo. Além destes, a biomassa microbiana, que representa a parte viva da matéria orgânica do solo excluídas raízes e animais maiores do que $5 \times 10^{3} \mu \mathrm{m}^{3}$, constitui-se em importante agente regulador do processo de decomposição de resíduos orgânicos e ciclagem de nutrientes (HUNGRIA et al., 2009).

$\mathrm{O}$ quociente metabólico $\left(\mathrm{qCO}_{2}\right)$, que indica a quantidade de $\mathrm{CO}_{2}$ produzido por unidade de carbono da biomassa microbiana, permite relacionar a perda de carbono para a atmosfera com a incorporação deste aos tecidos microbianos (ANDERSON; DOMSCH, 1990; ANDERSON;
DOMSCH, 1993). O quociente microbiano (qMIC), definido pela relação entre o carbono da biomassa microbiana e o do solo, permite dimensionar quanto do carbono orgânico do solo está imobilizado na biomassa microbiana e assim avaliar a eficiência dos microrganismos na imobilização deste elemento (ANDERSON; DOMSCH, 1989).

Na região amazônica predominam solos frágeis, seja quimicamente, no caso dos altamente intemperizados, como os Latossolos, Argissolos e Plintossolos, ou fisicamente, em estrutura, no caso dos da formação Solimões (WADT, 2002). No Acre se encontram as duas situações, evidenciando a necessidade de práticas de cultivo que aliem a manutenção da biodiversidade, o acúmulo de matéria orgânica e a melhoria das propriedades biológicas do solo.

O objetivo deste trabalho foi avaliar o efeito de plantas de cobertura em cultivo consorciado de maracujá, abacaxi, mandioca e milho sobre a atividade biológica do solo em período chuvoso e de estiagem.

\section{MATERIAL E MÉTODOS}

$\mathrm{O}$ experimento foi realizado no período de novembro de 2009 a novembro de 2011 no município de Rio Branco, AC

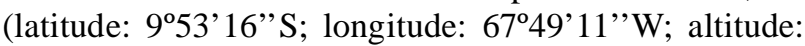
$170 \mathrm{~m}$; declividade de $0,02 \mathrm{~m} \mathrm{~m}^{-1}$ ). O clima da região é quente e úmido, do tipo Am segundo a classificação de Köppen, com temperaturas médias anuais em torno $24,5^{\circ} \mathrm{C}$, umidade relativa do ar de $84 \%$ e a precipitação pluviométrica anual variando de 1.700 a $2.400 \mathrm{~mm}$. Os dados meteorológicos do período de avaliação estão disponíveis na Tabela 1.

$\mathrm{O}$ delineamento experimental utilizado foi o de blocos casualizados em parcelas subdivididas com quatro repetições. A parcela principal foi constituída por quatro épocas de avaliação (março, maio, agosto e outubro de 2011) e as sub-parcelas por cinco coberturas de solo (feijão-de-porco, crotalária, puerária, amendoim forrageiro e plantas espontâneas) cultivadas em duas ruas de maracujazeiro paralelas medindo $9 \times 4 \mathrm{~m}$ cada. A parcela útil foi constituída em cada sub-parcela por uma amostra de solo composta por quatro amostras simples.

O solo do experimento foi classificado como Argissolo Amarelo Alítico plíntico (EMPRESA BRASIILEIRA DE PESQUISA AGROPECUÁRIA, 2006). Sua análise química na camada de $0-20 \mathrm{~cm}$ realizada segundo Empresa Brasileira de Pesquisa Agropecuária (1997) revelou os seguintes atributos de fertilidade: $\mathrm{pH}\left(\mathrm{H}_{2} \mathrm{O}\right) 5,4$; matéria orgânica: $18 \mathrm{~g} \mathrm{dm}^{-3}$; $\mathrm{P}$ (Mehlich-1): $7 \mathrm{mg} \mathrm{dm}^{-3}$; K: 2,6 $\mathrm{mmol}_{\mathrm{c}} \mathrm{dm}^{-3}$; Ca: 27 mmol $\mathrm{dm}^{-3} ; \mathrm{Mg}: 16 \mathrm{mmol}_{\mathrm{c}} \mathrm{dm}^{-3} ; \mathrm{Al}: 1 \mathrm{mmol}_{\mathrm{c}} \mathrm{dm}^{-3}$; H+Al: $41 \mathrm{mmolc} \mathrm{dm}^{-3}$; Fe: $530 \mathrm{mg} \mathrm{dm}^{-3}$; Cu: $1,6 \mathrm{mg} \mathrm{dm}^{-3}$; Mn: $99 \mathrm{mg} \mathrm{dm}^{-3} ; \mathrm{Zn}: 2,6 \mathrm{mg} \mathrm{dm}^{-3}$; B: $0,17 \mathrm{mg} \mathrm{dm}^{-3}$. 
Tabela 1 - Precipitação, temperatura e umidade relativa do ar durante o período de avaliação da atividade biológica do solo (janeiro a dezembro de 2011), Sítio Ecológico Seridó, Rio Branco, Acre, 2011

\begin{tabular}{lccccc}
\hline \multirow{2}{*}{ Mês } & \multirow{2}{*}{ Precipitação $(\mathrm{mm})$} & \multicolumn{3}{c}{ Temperatura $\left({ }^{\circ} \mathrm{C}\right)$} & \multirow{2}{*}{ Umidade Relativa do Ar $(\%)$} \\
\cline { 2 - 5 } & & Máxima & Mínima & Média & \\
\hline Janeiro & 116,9 & 30,3 & 22,7 & 25,6 & 87 \\
Fevereiro & 176,4 & 29,9 & 22,3 & 25,4 & 88 \\
Março & 263,3 & 30,5 & 22,5 & 25,4 & 88 \\
Abril & 213,5 & 31,1 & 22,0 & 25,5 & 88 \\
Maio & 50,0 & 31,0 & 20,4 & 24,8 & 84 \\
Junho & 21,8 & 31,2 & 20,0 & 24,6 & 82 \\
Julho & 1,8 & 32,6 & 18,5 & 24,4 & 76 \\
Agosto & 30,9 & 33,5 & 18,4 & 24,8 & 68 \\
Setembro & 116,8 & 33,6 & 21,1 & 26,1 & 78 \\
Outubro & 99,9 & 32,2 & 22,1 & 26,0 & 84 \\
Novembro & 290,0 & 32,3 & 22,5 & 26,5 & 81 \\
Dezembro & 127,2 & 31,2 & 22,8 & 25,9 & 87 \\
\hline
\end{tabular}

Fonte: Estação meteorológica da Universidade Federal do Acre, distante $10 \mathrm{~km}$ da área experimental

Com objetivo de elevar os teores de $\mathrm{Ca}$ e $\mathrm{Mg}$ do solo da área experimental, foi aplicado à lanço $1.000 \mathrm{~kg} \mathrm{ha}^{-1}$ de calcário dolomítico com $92 \%$ de PRNT, seguido de gradagem mecanizada com grade-aradora.

Após o preparo da área foi semeado o milho cv. Bandeirante (variedade) no espaçamento de $1 \mathrm{~m}$ entre linhas na densidade de 5 plantas $\mathrm{m}^{-1}$, totalizando 44.192 plantas $\mathrm{ha}^{-1}$. O transplantio do maracujazeiro para o local definitivo foi realizado em novembro/2009, no momento de emissão da $1^{\text {a }}$ gavinha, no espaçamento de 4,0 x 3,0 m (833 plantas ha-1), em covas de 40 × 40 × 40 $\mathrm{cm}$, adubadas com $12 \mathrm{~L}$ de esterco de curral, $500 \mathrm{~g}$ de calcário e $200 \mathrm{~g}$ de termofosfato magnesiano.

Após a capina do milho, realizada no estádio V2, foi plantado o abacaxizeiro em linhas quádruplas espaçadas 4,0 x $0,40 \times 0,40 \times 1,00 \mathrm{~m}\left(9.200\right.$ plantas $\left.\mathrm{ha}^{-1}\right)$ entre as linhas de maracujazeiro. Depois do plantio do abacaxi, foram semeados feijão-de-porco (6.157 plantas ha $\left.{ }^{-1}\right)$, crotalária (8.704 plantas ha $\left.{ }^{-1}\right)$, puerária (10.000 plantas ha ${ }^{-1}$ ) e plantado amendoim forrageiro, entre as linhas de abacaxizeiro e a linha de maracujazeiro. A mandioca foi plantada após a colheita do milho em duas linhas paralelas às linhas laterais do abacaxi, numa densidade de 4.600 covas ha' ${ }^{-1}$.

Foram realizadas duas adubações de cobertura no maracujazeiro (fevereiro/2010 e fevereiro/2011), com 12 litros de cama de frango enriquecido com sulfato de potássio $\left(20 \mathrm{~kg} \mathrm{~m}^{-3}\right)$ e bórax $\left(3 \mathrm{~kg} \mathrm{~m}^{-3}\right)$. Todos os insumos e práticas utilizadas estão de acordo com a Instrução Normativa $\mathrm{n}^{\circ} .46$ de 6 de outubro de 2011, que normatiza a produção orgânica vegetal no Brasil.
A fitomassa residual do ano anterior à avaliação foi constituída de colmos, folhas e flores do milho, parte aérea da mandioca, plantas de cobertura e vegetação espontânea. Os resíduos do milho e da mandioca foram coletados no momento da colheita. As folhas senescentes da mandioca, maracujazeiro, crotalária e feijão-de-porco foram recolhidas com coletores de madeira (quadrado de Pearson) forrados com tela, medindo $0,50 \times 0,50 \mathrm{~m}$, colocados abaixo do dossel. A coleta manual das folhas senescentes de puerária e amendoim forrageiro foram realizadas quinzenalmente, sempre na mesma área de 0,50 x 0,50 m. Antes de cada capina coletaram-se amostras da parte aérea da vegetação espontânea de uma área de 0,50 x 0,50 m para quantificar a biomassa dessa vegetação. Toda biomassa coletada foi secada em estufa a $65^{\circ} \mathrm{C}$ até obter-se massa constante.

A produção de biomassa seca foi de $25.221,3 \mathrm{~kg}$ ha $^{-1}$ para a puerária, $25.090,3 \mathrm{~kg} \mathrm{ha}^{-1}$ para feijão-de-porco, $24.011,1 \mathrm{~kg} \mathrm{ha}^{-1}$ para crotalária, $21.885,8 \mathrm{~kg} \mathrm{ha}^{-1}$ para amendoim forrageiro e $18.261,0 \mathrm{~kg} \mathrm{ha}^{-1}$ para plantas espontâneas.

Para avaliar a respiração basal, a biomassa microbiana e os quocientes metabólico e microbiano foram realizadas coletas de solo na profundidade de 0 a $10 \mathrm{~cm}$ em quatro épocas do ano de duas estações distintas, chuvosa $(26 / 03 / 11$ e 19/10/11) e seca $(07 / 05 / 11$ e 01/08/11). A determinação da respiração basal do solo foi efetuada a partir de $100 \mathrm{~g}$ de solo peneirado e incubado em frascos de vidro hermeticamente fechados contendo $20 \mathrm{~mL}$ de hidróxido de sódio $(\mathrm{NaOH}) 0,5 \mathrm{~N} \mathrm{~L}^{-1}$ para a captura do $\mathrm{CO}_{2}$ liberado pela amostra. Após incubação por 7 dias 
efetuou-se a titulação do $\mathrm{NaOH}$, recolhido dos recipientes do interior dos frascos, com $\mathrm{HCl} 0,5 \mathrm{~N}$ acrescido de $2 \mathrm{~mL}$ de $\mathrm{BaCl}_{2} 10 \%(\mathrm{~m} / \mathrm{v})$ para precipitação do carbonato e 2 gotas de fenolftaleína $1 \%(\mathrm{~m} / \mathrm{v})$ como indicador (SILVA; AZEVEDO; DE-POLLI, 2007).

A quantidade de $\mathrm{C}-\mathrm{CO}_{2}$ liberado pelas amostras foi calculada de acordo com a equação 1 , proposta por Stotzky (1965).

$R B=((B-V) . N . E . F U . F D .10) / T$

em que: $R B=$ respiração basal expressa em mg C- $\mathrm{CO}_{2}$ $\mathrm{kg}^{-1}$ solo $\mathrm{h}^{-1} ; B=$ volume em $\mathrm{mL}$ de $\mathrm{HCl}$ gasto na prova em branco (controle); $V=$ volume em $\mathrm{mL}$ de $\mathrm{HCl}$ gasto na amostra exposta ao solo; $N=$ normalidade do $\mathrm{HCl} ; E=$ equivalente-grama do carbono; $F U=$ fator umidade obtido pelo quociente entre as massas de solo úmida e seca; $F D=$ fator diluição obtido pelo quociente entre os volumes de $\mathrm{NaOH}$ usados na incubação e na titulação; 10 = fator de correção de g para kg; $T$ = tempo de incubação em horas.

A biomassa microbiana foi obtida pelo método da respiração induzida (ANDERSON; DOMSCH, 1978) utilizando-se como substrato $0,5 \mathrm{~g}$ de açúcar refinado misturado a $100 \mathrm{~g}$ de solo peneirado e incubado em frascos de vidro hermeticamente fechados contendo $20 \mathrm{~mL}$ de $\mathrm{NaOH} 0,5 \mathrm{~N}$ para a captura do $\mathrm{CO}_{2}$ liberado pela amostra. Após incubação por 4 horas efetuou-se a titulação do $\mathrm{NaOH}$, recolhido dos recipientes do interior dos frascos, com $\mathrm{HCl} 0,5 \mathrm{~N}$ acrescido de $2 \mathrm{~mL}$ de $\mathrm{BaCl}_{2} 10 \%(\mathrm{~m} / \mathrm{v})$ para precipitação do carbonato e 2 gotas de fenolftaleína $1 \%(\mathrm{~m} / \mathrm{v})$ como indicador. $\mathrm{O}$ C- $\mathrm{CO}_{2}$ liberado pelas amostras de solo pelo método da respiração induzida pelo substrato foi quantificado da mesma forma que para respiração basal e a biomassa microbiana calculada pela seguinte expressão (Equação 2):

$y=40,04 x+0,37$

onde $y=$ biomassa microbiana em mg C-mic. $\mathrm{kg}^{-1}$ solo e $x=\mathrm{mg}$ de $\mathrm{C}-\mathrm{CO}_{2} \mathrm{~kg}^{-1}$ solo $\mathrm{h}^{-1}$ liberado na respiração induzida pela adição da glicose.

O quociente metabólico do solo $\left(\mathrm{qCO}_{2}\right)$ foi obtido, segundo recomendado por Anderson e Domsch (1993), pela razão entre os resultados da respiração basal (RB) e os da biomassa microbiana (BM) da mesma amostra, ou seja $\mathrm{qCO}_{2}=\mathrm{RB} / \mathrm{BM}$ e o quociente microbiano (qMIC), pela razão entre a BM e o carbono orgânico total do solo, conforme Anderson e Domsch (1989).

Aumidade do solo considerada nas determinações das respirações basal e induzida foi obtida à partir de amostras de $100 \mathrm{~g}$ de solo, colocadas em estufa de circulação de ar forçada a $105^{\circ} \mathrm{C}$.

Também, avaliou-se a respiração edáfica a qual foi determinada mediante uso de câmaras estáticas, constituídas de tubos de cloreto de polivinil rígido
(PVC) de $200 \mathrm{~mm}$ de diâmetro e $50 \mathrm{~cm}$ de altura, inseridas em cada área a aproximadamente $5 \mathrm{~cm}$ de profundidade. Em cada câmara foi acondicionado um recipiente plástico contendo $30 \mathrm{~mL}$ de solução de $\mathrm{NaOH} 0,5 \mathrm{~N}$ para captura do $\mathrm{CO}_{2}$ e, em cinco destas, consideradas como controle (branco), efetuou-se a vedação de seus fundos com plástico para evitar que nas mesmas houvesse a captura do $\mathrm{CO}_{2}$ do solo pela solução de $\mathrm{NaOH}$ em seu interior. Após incubação por 48 horas efetuou-se a titulação do $\mathrm{NaOH}$, recolhido dos recipientes do interior dos tubos, com $\mathrm{HCl} 0,5 \mathrm{~N}$ acrescido de $2 \mathrm{~mL}$ de $\mathrm{BaCl}_{2} \quad 10 \%(\mathrm{~m} / \mathrm{v})$ para precipitação do carbonato e 2 gotas de fenolftaleína $1 \%(\mathrm{~m} / \mathrm{v})$ como indicador (CAMPOS, 2006; OLIVEROS, 2008).

A quantidade de $\mathrm{C}-\mathrm{CO}_{2}$ emitido por unidade de superfície foi calculada de acordo com a equação 3, proposta por Anderson (1982).

$R E=((B-V) N E) /(A . T)$

em que: $R E=$ respiração edáfica expressa em $\mathrm{mg} \mathrm{C}-\mathrm{CO}_{2} \mathrm{~m}^{-2} \mathrm{~h}^{-1}$; $B=$ volume em $\mathrm{mL}$ de $\mathrm{HCl}$ gasto na prova em branco (controle); $V=$ volume em $\mathrm{mL}$ de $\mathrm{HCl}$ gasto na amostra exposta ao solo; $N=$ normalidade do $\mathrm{HCl} ; E=$ equivalentegrama do carbono; $A$ = área em $\mathrm{m}^{2}$ da superfície do solo amostrada; $T=$ tempo de incubação em horas.

Para a análise estatística efetuou-se primeiramente a verificaçãodanormalidade dos erros peloteste de Shapiro-Wilk e da homogeneidade das variâncias pelo teste de Bartlett. Para as variáveis que não atenderam a normalidade dos erros e/ou a homogeneidade das variâncias efetuou-se a transformação dos dados. Posteriormente procedeu-se a análise de variância com os dados originais e/ou transformados e quando o valor $\mathrm{F}$ indicou existir diferença entre os tratamentos fez-se a comparação de suas médias pelo teste de Scott-Knott. A comparação das médias dos solos cultivados sob floresta foi feita pelo teste t de Student.

\section{RESULTADOS E DISCUSSÃO}

Verificou-se diferença $(P<0,05)$ da interação entre coberturas de solo e épocas de avaliação para a respiração basal do solo (Tabela 2), respiração edáfica (Tabela 3), biomassa microbiana (Tabela 4), o quociente metabólico (Tabela 5) e quociente microbiano (Tabela 6). A umidade do solo foi alterada apenas entre as épocas de coleta (Tabela 2).

Os maiores índices de respiração basal (Tabela 2) e edáfica (Tabela 3) observadas no mês de maio em todas as coberturas indicam que nesta época a condição de umidade do solo proporcionada pelo final da estação chuvosa e início da seca é a mais favorável à manutenção da atividade aeróbica dos microrganismos (basal) e em conjunto com invertebrados e raízes de plantas (edáfica). Nos outros 
períodos há maior restrição de oxigênio na estação chuvosa (outubro a março) e de água com o avançar da estação seca (agosto) (Tabela 1). Zanchi et al. (2012) verificaram na Amazônia brasileira que a respiração do solo foi reduzida em até $27 \%$ para chuvas de $22 \mathrm{~mm}$. Porém, no presente trabalho, em maio, quando se observou redução da precipitação (Tabela 1) as emissões de $\mathrm{C}-\mathrm{CO}_{2}$ pelas respirações basal (Tabela 2) e edáfica (Tabela 3 ) foram maiores que os demais períodos avaliados.

Ao final do período chuvoso (maio) a respiração basal foi maior em solo coberto com crotalária e feijão-deporco (Tabela 2). Segundo Fanin et al. (2010) a qualidade da biomassa vegetal tem forte relação com a respiração do solo, em geral, pelo maior conteúdo de $\mathrm{P}$ e formas de $\mathrm{C}$ que promovem acesso mais rápido à energia e, além disso, pela ação antrópica causada no manejo das plantas que realizam simbiose com microrganismos. Segundo Zhang e Fang (2007) a adubação verde associada à orgânica aumenta o C, o N e o P da biomassa microbiana e melhoria dos atributos físicos do solo, fatores estes que contribuem com a atividade microbiana.

O feijão-de porco proporcionou maior respiração edáfica no final do período chuvoso (Tabela 3). De acordo com Sá (2001) a produção de $\mathrm{CO}_{2}$ no interior do solo está relacionada à atividade biológica, incluindo a respiração das raízes e a decomposição da matéria orgânica do solo pela atividade microbiana, mas segundo Fialho et al. (2006) depende da composição da biomassa microbiana.

A cobertura com amendoim forrageiro proporcionou maior respiração basal e respiração edáfica nos meses de março, outubro e agosto, inclusive comparado ao solo sob floresta nativa (Tabelas 2 e 3 ). Este comportamento pode ter sido influenciado também pela alta capacidade de produção de biomassa e ciclagem de nutrientes, principalmente nitrogênio por meio da fixação biológica, uma vez que o amendoim forrageiro possui alta produtividade de biomassa (ESPINDOLA et al., 2006), maior relação de raízes/parte aérea e colonização por várias espécies de fungos micorrízicos arbusculares (MIRANDA et al., 2010). Além disso, aumenta o teor de C e P microbiano mineralizado e disponível comparativamente às outras espécies como pueráia ( $P$. phaseoloides) e siratro (M. atropurpureum) (DUDA et al., 2003).

A biomassa microbiana foi maior durante o período mais seco (agosto) em solo coberto com todas as espécies de adubo verde avaliadas exceto em solo coberto com plantas espontâneas, que registrou mesma biomassa nos períodos de maio e agosto (Tabela 4). Este fato pode ser atribuído à diversidade de plantas que proporciona maior regularidade do substrato em condições estressantes (XUE-MEI et al., 2007) e maiores conteúdos de carboidratos, ácidos carboxílicos, aminas, amidas, aminoácidos e polímeros (LORANGERMERCIRISA et al., 2006) fatores estes que podem ter contribuído para a manutenção da biomassa microbiana em solo coberto com plantas espontâneas em período de baixa umidade no solo (agosto).

O solo coberto por plantas espontâneas aumentou a biomassa microbiana no período de maior precipitação pluviométrica (março) e no período intermediário (maio) quando comparado às demais coberturas (Tabela 4). Maior

Tabela 2 - Respiração basal (mg C-CO $\mathrm{kg}^{-1}$ solo dia $\left.^{-1}\right)$ em resposta à cinco coberturas de solo e quatro épocas de avaliação, em cultivo múltiplo de maracujá, abacaxi, milho e mandioca sob sistema orgânico de produção. Sítio Ecológico Seridó, Rio Branco, Acre, 2011

\begin{tabular}{lllll}
\hline \multirow{2}{*}{ Cobertura do solo } & \multicolumn{2}{c}{ Estação Chuvosa } & \multicolumn{2}{c}{ Estação Seca } \\
\cline { 2 - 5 } & Março & Outubro & Maio & Agosto \\
\hline Plantas espontâneas & $17,0 \mathrm{bB}$ & $17,4 \mathrm{bB}^{\mathrm{ns}}$ & $27,3 \mathrm{bA}$ & $15,6 \mathrm{bB}$ \\
Amendoim forrageiro & $20,9 \mathrm{aB}$ & $20,3 \mathrm{aB}$ & $24,5 \mathrm{bA}$ & $18,7 \mathrm{aB}^{\mathrm{ns}}$ \\
Puerária & $17,5 \mathrm{bB}^{\mathrm{ns}}$ & $16,7 \mathrm{bB}^{\mathrm{ns}}$ & $26,2 \mathrm{bA}$ & $15,0 \mathrm{bC}$ \\
Crotalária & $19,1 \mathrm{aB}^{\mathrm{ns}}$ & $18,0 \mathrm{bB}^{\mathrm{ns}}$ & $30,2 \mathrm{aA}$ & $16,4 \mathrm{bB}$ \\
Feijão-de-porco & $17,1 \mathrm{bB}$ & $16,5 \mathrm{bB}$ & $32,1 \mathrm{aA}$ & $14,6 \mathrm{bC}$ \\
Solo sob floresta & 18,9 & 18,3 & 10,6 & 18,6 \\
Umidade do solo/coberturas $(\%)$ & 20,7 & 18,2 & 18,2 & 6,9 \\
Umidade do solo/floresta $(\%)$ & 20,2 & 16,8 & 16,8 & 5,7 \\
\hline
\end{tabular}

$\mathrm{CV}$ (época do ano) $=2,39 \%$; CV (cobertura de solo) $=3,35 \%$

$\mathrm{F}($ Época $=237,7 * * \mathrm{~F}($ Cobertura $)=9,1 * * \mathrm{~F}($ Época $\mathrm{x}$ Cobertura $)=6,4 * *$

Médias seguidas de letras distintas, minúsculas na coluna e maiúsculas na linha, diferem $(P<0,05)$ pelo teste de Scott-Knott ${ }^{(1)}$. ${ }^{(2)}$ Médias originais cujos dados foram transformados em $\log (\mathrm{x}) \mathrm{e}^{(3)} \operatorname{arcsen} \sqrt{\mathrm{x}} / 100$ para atender os pressupostos da análise de variância. Média seguida de "ns" não difere $(P>0,05)$ da média de solo de floresta pelo teste $\mathrm{t}$ de Student $*$ significativo a $5 \%, * *$ significativo a $1 \%$ e ns não significativo pelo teste $\mathrm{F}$ 
Tabela 3 - Respiração edáfica $\left(\mathrm{mg} \mathrm{C}-\mathrm{CO}_{2} \mathrm{~m}^{-2} \mathrm{~h}^{-1}\right)$ de solos em resposta à cinco coberturas de solo e quatro épocas de avaliação, em cultivo múltiplo de maracujá, abacaxi, milho e mandioca sob sistema orgânico de produção. Sítio Ecológico Seridó, Rio Branco, Acre, 2011

\begin{tabular}{lllll}
\hline \multirow{2}{*}{ Cobertura do solo } & \multicolumn{2}{c}{ Estação Chuvosa } & \multicolumn{2}{c}{ Estação Seca } \\
\cline { 2 - 5 } & Março & Outubro & Maio & Agosto \\
\hline Plantas espontâneas & $17,6 \mathrm{aD}$ & $23,3 \mathrm{aC}$ & $63,4 \mathrm{dA}$ & $36,1 \mathrm{cB}$ \\
Amendoim forrageiro & $17,3 \mathrm{aD}$ & $22,1 \mathrm{aC}$ & $65,5 \mathrm{cA}$ & $42,9 \mathrm{aB}$ \\
Puerária & $17,4 \mathrm{aD}$ & $23,4 \mathrm{aC}$ & $69,6 \mathrm{bA}$ & $40,5 \mathrm{bB}$ \\
Crotalária & $16,3 \mathrm{aD}$ & $20,8 \mathrm{aC}$ & $65,8 \mathrm{cA}$ & $33,9 \mathrm{cB}$ \\
Feijão-de-porco & $17,8 \mathrm{aD}$ & $21,4 \mathrm{aC}$ & $72,4 \mathrm{aA}$ & $34,4 \mathrm{cB}$ \\
Solo sob floresta & 14,97 & 18,69 & 57,76 & 38,75 \\
\hline
\end{tabular}

$\mathrm{CV}$ (época do ano) $=3,82 \% ; \mathrm{CV}$ (cobertura de solo) $=5,45 \%$

$\mathrm{F}\left(\right.$ Época $=5362,4 * * \mathrm{~F}($ Cobertura $)=17,4^{* *} \mathrm{~F}($ Época $\mathrm{x}$ Cobertura $)=15,8^{* *}$

*Médias seguidas de letras distintas, minúsculas na coluna e maiúsculas na linha, diferem $(P<0,05)$ pelo teste de Scott-Knott ${ }^{(1)}$. Média seguida de "ns" não difere $(P>0,05)$ da média de solo de floresta pelo teste t de Student $*$ significativo a $5 \%, * *$ significativo a $1 \%$ e ns não significativo pelo teste $\mathrm{F}$

Tabela 4 - Biomassa microbiana (mg C-Cmic kg-1 solo) de solos em resposta à cinco coberturas de solo e quatro épocas de avaliação, em cultivo múltiplo de maracujá, abacaxi, milho e mandioca sob sistema orgânico de produção. Sítio Ecológico Seridó, Rio Branco, Acre, 2011

\begin{tabular}{|c|c|c|c|c|}
\hline \multirow{2}{*}{ Cobertura do solo } & \multicolumn{2}{|c|}{ Estação Chuvosa } & \multicolumn{2}{|c|}{ Estação Seca } \\
\hline & Março & Outubro & Maio & Agosto \\
\hline Plantas espontâneas & $1158,4 \mathrm{aB}$ & $846,3 \mathrm{aC}^{\mathrm{ns}}$ & $1514,8 \mathrm{aA}$ & $1444,5 \mathrm{aA}$ \\
\hline Amendoim forrageiro & $701,7 \mathrm{bB}$ & $817,6 \mathrm{aB}$ & $886,1 \mathrm{bB}$ & $1455,5 \mathrm{aA}^{\mathrm{ns}}$ \\
\hline Puerária & $835,7 \mathrm{bB}^{\mathrm{ns}}$ & $741,5 \mathrm{aB}$ & $857,5 \mathrm{bB}$ & $1357,7 \mathrm{aA}$ \\
\hline Crotalária & $743,1 \mathrm{bB}$ & $899,9 \mathrm{aB}^{\mathrm{ns}}$ & $806,7 \mathrm{bB}$ & $1219,9 \mathrm{aA}$ \\
\hline Feijão-de-porco & $631,7 \mathrm{bB}$ & $799,2 \mathrm{aB}$ & $835,2 \mathrm{bB}$ & $1633,2 \mathrm{aA}$ \\
\hline Solo sob floresta & 766,1 & 820,4 & 908,6 & 1445,2 \\
\hline CV (época do ano) $=15,01 \%$; & e solo) $=15,0$ & & & \\
\hline
\end{tabular}

*Médias seguidas de letras distintas, minúsculas na coluna e maiúsculas na linha, diferem $(P<0,05)$ pelo teste de Scott-Knott ${ }^{(1)}$. Média seguida de "ns" não difere $(P>0,05)$ da média de solo de floresta pelo teste t de Student * significativo a $5 \%, * *$ significativo a $1 \%$ e ${ }^{\text {ns }}$ não significativo pelo teste $\mathrm{F}$

diversidade de plantas, como tem ocorrido na vegetação espontânea, aumenta a atividade e a biomassa microbiana do solo (HUNGRIA et al., 2009; LORANGERMERCIRISA et al., 2006; XUE-MEI et al., 2007).

$\mathrm{O}$ quociente metabólico $\left(\mathrm{qCO}_{2}\right)$ foi influenciado pelas plantas de cobertura apenas no período de maior precipitação pluviométrica (março) com baixo valor em solo sob plantas espontâneas (Tabela 5). Esta situação indica que o consumo de energia armazenada na MOS pelos microorganismos resulta em alta eficiência na mineralização sendo maior quando aumenta a diversidade de plantas no manejo do solo (HUNGRIA et al., 2009). Essa característica contribui para tornar as plantas espontâneas em mais uma alternativa de adubação verde para a fruticultura.

No período com regime hídrico intermediário (maio), com exceção de solo coberto com plantas espontâneas, o quociente metabólico manteve-se elevado, semelhante ao observado no período de maior pluviosidade (março) em solo coberto com crotalária, feijão-de-porco e, também, de outubro a março em solo coberto com amendoim forrageiro (Tabela 5). Os menores valores foram observados no período de menor umidade do solo (agosto). $\mathrm{O}$ elevado $\mathrm{qCO}_{2}$ em maio é explicado pela intensa atividade microbiana (Tabela 2) no mesmo período, em decorrência do acúmulo de biomassa vegetal 


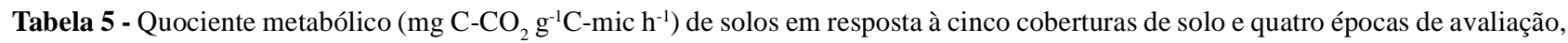
em cultivo múltiplo de maracujá, abacaxi, milho e mandioca sob cultivo orgânico. Sítio Ecológico Seridó, Rio Branco, Acre, 2011

\begin{tabular}{|c|c|c|c|c|}
\hline \multirow{2}{*}{ Cobertura do solo } & \multicolumn{2}{|c|}{ Estação Chuvosa } & \multicolumn{2}{|c|}{ Estação Seca } \\
\hline & Março & Outubro & Maio & Agosto \\
\hline Plantas espontâneas & $0,63 \mathrm{bC}$ & $1,37 \mathrm{aA}$ & $0,88 \mathrm{aB}$ & $0,47 \mathrm{aC}$ \\
\hline Amendoim forrageiro & $1,27 \mathrm{aA}^{\mathrm{ns}}$ & $1,08 \mathrm{aA}$ & $1,08 \mathrm{aA}$ & $0,52 \mathrm{aB}$ \\
\hline Puerária & $0,97 \mathrm{aB}$ & $0,97 \mathrm{aB}$ & $1,32 \mathrm{aA}$ & $0,46 \mathrm{aC}$ \\
\hline Crotalária & $1,11 \mathrm{aA}$ & $0,78 \mathrm{aB}$ & $1,26 \mathrm{aA}$ & $0,57 \mathrm{aB}^{\mathrm{ns}}$ \\
\hline Feijão-de-porco & $1,29 \mathrm{aA}^{\mathrm{ns}}$ & $0,85 \mathrm{aB}$ & $1,33 \mathrm{aA}$ & $0,38 \mathrm{aC}$ \\
\hline Solo sob floresta & 1,30 & 1,15 & 0,42 & 0,50 \\
\hline
\end{tabular}

*Médias seguidas de letras distintas, minúsculas na coluna e maiúsculas na linha, diferem $(P<0,05)$ pelo teste de Scott-Knott ${ }^{(1)}$. ${ }^{(2)}$ Médias originais cujos dados foram transformados em arcsen $\sqrt{ } \mathrm{x} / 100$ para atender os pressupostos da análise de variância. Média seguida de "ns" não difere $(P>0,05)$ da média de solo de floresta pelo teste $\mathrm{t}$ de Student * significativo a $5 \%$, ** significativo a $1 \%$ e ${ }^{\text {ns }}$ não significativo pelo teste $\mathrm{F}$

e da condição de baixa precipitação pluviométrica e manutenção da umidade do solo. Alves et al. (2011) relatam que a incorporação de resíduos de culturas ao solo aumenta o quociente metabólico numa relação inversa com a biomassa microbiana sugerindo que em condições de maiores teores de $\mathrm{C}$, pode ocorrer aumento desta e diminuição na atividade metabólica.

O quociente microbiano (qMic) foi maior em solo coberto por plantas espontâneas no período de maior pluviosidade (março) e no período intermediário (maio) comparado às demais coberturas. No período de menor pluviosidade e umidade do solo (agosto) o qMIC foi maior que as demais épocas (Tabela 6).

Verificou-se que o qMIC aumentou da época úmida para a época seca, enquanto o $\mathrm{qCO}_{2}$ foi reduzido.
Esse aumento do qMIC é decorrente da alta biomassa microbiana no período seco (Tabela 4), respondendo por 10,7 a $14,6 \%$ do carbono do solo, resultante da biomassa vegetal acumulada durante o cultivo e mineralizada em solo úmido durante o período chuvoso. Segundo Martins et al. (2010) os atributos microbianos do solo variam em função da sazonalidade e da condição hídrica.

Normalmente o carbono da biomassa microbiana (CBM) representa de 1 a $4 \%$ do carbono orgânico total e, de modo geral, valores de qMIC inferiores a $1 \%$ podem ser atribuídos a algum fator limitante à atividade da biomassa microbiana (SILVA et al., 2012). Assim, os menores valores de qMIC na época chuvosa, podem ser decorrentes da disponibilidade de oxigênio no solo. De acordo com Alves et al. (2011) em condições de solo seco o CBM é maior em áreas de pastagem com braquiária pelo fato do sistema

Tabela 6 - Quociente microbiano (\%) de solos em resposta à cinco coberturas de solo e quatro épocas de avaliação, em cultivo múltiplo de maracujá, abacaxi, milho e mandioca em cultivo orgânico de produção. Sítio Ecológico Seridó, Rio Branco, Acre, 2011

\begin{tabular}{|c|c|c|c|c|}
\hline \multirow{2}{*}{ Cobertura do solo } & \multicolumn{2}{|c|}{ Estação Chuvosa } & \multicolumn{2}{|c|}{ Estação Seca } \\
\hline & Março & Outubro & Maio & Agosto \\
\hline Plantas espontâneas & $10,7 \mathrm{aB}$ & $7,7 \mathrm{aB}$ & $14,0 \mathrm{aA}$ & $13,1 \mathrm{aA}$ \\
\hline Amendoim forrageiro & $5,5 \mathrm{bB}$ & $6,3 \mathrm{aB}$ & $6,9 \mathrm{bB}$ & $11,4 \mathrm{aA}$ \\
\hline Puerária & $6,6 \mathrm{bB}$ & $5,9 \mathrm{aB}$ & $6,8 \mathrm{bB}$ & $10,7 \mathrm{aA}$ \\
\hline Crotalária & $6,9 \mathrm{bB}$ & $8,5 \mathrm{aB}$ & $7,6 \mathrm{bB}$ & $11,2 \mathrm{aA}$ \\
\hline Feijão-de-porco & $5,7 \mathrm{bB}$ & $7,2 \mathrm{aB}$ & $7,2 \mathrm{bB}$ & $14,6 \mathrm{aA}$ \\
\hline \multicolumn{5}{|c|}{$\mathrm{CV}($ época do ano $)=14,2 \% ; \mathrm{CV}($ cobertura de solo $)=24,9 \%$} \\
\hline \multicolumn{5}{|c|}{$\mathrm{F}\left(\right.$ Época $=63,1^{* *} \mathrm{~F}($ Cobertura $)=1,7^{\text {ns }} \mathrm{F}($ Época $\mathrm{x}$ Cobertura $)=5,1^{*}$} \\
\hline
\end{tabular}


radicular desta espécie ser abundante, volumoso e apresentar contínua renovação e elevado efeito rizosférico.

Os valores elevados de qMIC observados neste trabalho podem ter sido devidos a alta biomassa vegetal produzida, adubação orgânica e ausência de agrotóxicos. Segundo Freitas et al. (2011) em cultivo orgânico há maior micorrização e atividade microbiana do solo. Já em cultivo convencional com aplicação de agrotóxicos García-Orenes et al. (2010) observaram baixos níveis de respiração basal e de biomassa microbiana do solo.

\section{CONCLUSÕES}

1.Em condições de adequada umidade e oxigenação do solo a cobertura com crotalária potencializa a atividade microbiana juntamente com feijão de porco que proporciona maior respiração edáfica;

2.Em período com maior restrição de oxigênio o amendoim forrageiro mantém alta a atividade microbiana;

3.Em período seco a atividade metabólica é baixa indicando maior eficiência no uso do carbono e menor emissão de $\mathrm{CO}_{2}$ do solo;

4.Em período de maior precipitação pluviométrica a biomassa microbiana é alta em solo sob plantas espontâneas e elevada eficiência metabólica.

\section{REFERÊNCIAS}

ANDERSON, J. P. E; DOMSCH, K. H. A physiological method for the quantitative measurement of microbial biomass in soils. Soil Biology and Biochemistry, v. 10, n. 3, p. 215221, 1978.

ANDERSON, J. P. E. Soil respiration. In: PAGE, A. L.; MILLER, R. H.; KEENEY, D. R. (Ed.). Methods of soil analysis: chemical and microbiological properties. 2. ed. Madison: American Society of Agronomy, 1982. p. 831-871. v. 2.

ANDERSON, T. H., DOMSCH, K. H. Application of ecophysiological quotients $\left(\mathrm{qCO}_{2}\right.$ and $\left.\mathrm{qD}\right)$ on microbial biomasses from soils of different cropping histories. Soil Biology and Biochemistry, v. 22, n. 2, p. 251-255, 1990.

ANDERSON, T. H.; DOMSCH, K. H. Ratio of microbial biomass carbon to total organic carbon in arable soils. Soil Biology and Biochemistry, v. 21, n. 4, p. 471-479, 1989.

ANDERSON, J. P. E.; DOMSCH, K. H. The metabolic quotient $\left(\mathrm{qCO}_{2}\right)$ as a specific activity parameter to assess the effects of environmental conditions, such as $\mathrm{pH}$, on the microbial biomass of forest soils. Soil Biology and Biochemistry, v. 25, n. 3, p. 393-395, 1993.
ALVES, T. dos S. et al. Biomassa e atividade microbiana de solo sob vegetação nativa e diferentes sistemas de manejos. Acta Scientiarum Agronomy, v. 33, n. 2, p. 341-347, 2011.

BEZERRA, M. S.; OLIVEIRA, M. R. V. de; VASCONCELOS, S. D. Does the presence of weeds affect Bemisia tabaci (Gennadius) (Hemiptera: Aleyrodidae) infestation on tomato plants in a semi-arid agro-ecosystem? Neotropical Entomology, v. 33, n. 6, p. 769-775, 2004.

CAMPOS, B. C. Dinâmica do carbono em Latossolo Vermelho sob sistemas de preparo de solo e de culturas. 2006. 188 f. Tese (Doutorado em Ciência do Solo) - Centro de Ciências Rurais, Universidade Federal de Santa Maria, Santa Maria, 2006.

CASTRO, A. C. et al. Sistema silvipastoril na Amazônia: ferramenta para elevar o desempenho produtivo de búfalos. Ciência Rural, v. 38, n. 8, p. 2395-2402, 2008.

DUDA, G. P. et al. Perennial herbaceous legumes as live soil mulches and their effects on $\mathrm{c}, \mathrm{n}$ and $\mathrm{p}$ of the microbial biomass. Scientia Agricola, v. 60, n. 1, p. 139-147, 2003.

EMPRESA BRASIILEIRA DE PESQUISA AGROPECUÁRIA. Manual de métodos de análise de solo. 2. ed. Brasília: Centro Nacional de Pesquisa de Solos, 1997. 212 p. (Documentos, 1).

EMPRESA BRASILEIRA DE PESQUISA AGROPECUÁRIA. Sistema brasileiro de classificação de solos. (2. Ed.) Brasília: Centro Nacional de Pesquisa de Solos. 2006. 412 p.

ESPINDOLA, J. A. A. et al. Bananeiras consorciadas com leguminosas herbáceas perenes utilizadas como coberturas vivas. Pesquisa Agropecuária Brasileira, v. 41, n. 3, p. 415420, 2006.

FANIN, N. et al. Does variability in litter quality determine soil microbial respiration in an Amazonian rainforest? Soil Biology \& Biochemistry, v. 43, n. 5, p. 1014-1022, 2011.

FIALHO, J. S. et al. Indicadores da qualidade do solo em áreas sob vegetação natural e cultivo de bananeiras na Chapada do Apodi-CE. Revista Ciência Agronômica, v. 37, n. 3, p. 250-257, 2006.

FREITAS, N. O. et al. Soil biochemistry and microbial activity in vineyards under conventional and organic management at Northeast Brazil. Scientia Agricola, v. 68, n. 2, p. 223-229, 2011.

GARCÍA-ORENES, F. et al. Soil microbial biomass and activity under different agricultural management systems in a semiarid Mediterranean agroecosystem. Soil \& Tillage Research, v. 109, n. 2, p. 110-115, 2010.

HUNGRIA, M. et al. A. Soil microbial activity and crop sustainability in a longterm experiment with three soil-tillage and two crop-rotation systems. Applied Soil Ecology, v. 42, n. 3, p. 288-296, 2009.

LORANGER-MERCIRISA, G. et al. Rapid effects of plant species diversity and identity on soil microbial communities in experimental grassland ecosystems. Soil Biology \& Biochemistry, v. 38, n. 8, p. 2336-2343, 2006. 
LOSS, A. et al. Distribuição dos agregados e carbono orgânico influenciados por manejos agroecológicos. Acta Scientarum, v. 31, n. 3, p. 523-528, 2009.

MARTINS, C. M. et al. Atributos químicos e microbianos do solo de áreas em processo de desertificação no semiárido de Pernambuco. Revista Brasileira de Ciência do Solo, v. 34, n. 6, p. 1883-1890, 2010.

MIRANDA, E. M. et al. Comunidades de fungos micorrízicos arbusculares associados ao amendoim forrageiro em pastagens consorciadas no Estado do Acre, Brasil. Acta Amazônica, v. 40, p. 13-22, 2010.

OLIVEROS, L. F. C. Emissões de $\mathrm{CO}_{2}$ do solo sob preparo convencional e plantio direto em latossolo vermelho do Rio Grande do Sul. 2008. 80 f. Dissertação (Mestrado em Ciências do Solo) - Centro de Ciências Rurais, Universidade Federal de Santa Maria, Santa Maria, 2008.

PRIETO-BENÍTEZ, S.; MÉNDEZ, M. Effects of land management on the abundance and richness of spiders (Araneae): a meta-analysis. Biological Conservation, v. 144, n. 2, p. 683-691, 2011.

SÁ, J. C. de M. et al. Organic matter dynamics and carbon sequestration rates for a tillage chronosequence in a Brazilian Oxisol. Soil Science Society of America Journal, v. 65, n. 5, p. 1486-1499, 2001.

SAKONNAKHON, S. P. N. et al. A. Weeds - friend or foe? The role of weed composition on stover nutrient recycling efficiency. Field Crops Research, v. 97, n. 2/3, p. 238-247, 2006.
SILVA, A. C. da; HIRATA, E. K.; MONQUERO, P. A. Produção de palha e supressão de plantas daninhas por plantas de cobertura, no plantio direto do tomateiro. Pesquisa Agropecuária Brasileira, v. 44, n. 1, p. 22-28, 2009.

SILVA, C. F. da. et al. Florestais e pastagem no médio vale do Paraíba do Sul (RJ). Revista Brasileira de Ciência do Solo, v. 36, p.1680-1689, 2012.

SILVA, E. E. da; AZEVEDO, P. H. S.; DE-POLLI, H. Determinação da respiração basal (RBS) e quociente metabólico do solo $\left(\mathbf{q C O} \mathbf{C O}_{2}\right)$ Seropédica: Embrapa Agrobiologia, 2007. 4 p. (Comunicado técnico, 99).

STOTZKY, G. Microbial respiration. In: BLACK, C. A et al. (Ed.). Methods of soil analysis: chemical and microbiological properties. Madison: American Society of Agronomy, 1965. p. $1550-1572$. v. 2.

WADT, P. G. S. Manejo de solos ácidos do estado do Acre. Rio Branco, AC: Embrapa Acre, 2002. 28 p.

XUE-MEI, H. et al. Effects of vegetation type on soil microbial community structure and catabolic diversity assessed by polyphasic methods in North China. Journal of Environmental Sciences, v. 19, n. 10, p. 1228-1234, 2007.

ZANCHI, F. B. et al. Soil $\mathrm{CO}_{2}$ efflux in Central Amazonia: environmental and methodological effects. Acta Amazonica, v. 42, n. 1/2, p. 173-184, 2012.

ZHANG, M-K.; FANG, L. Effect of tillage, fertilizer and green manure cropping on soil quality at an abandoned brick making site. Soil \& Tillage Research, v. 93, n. 1, p. 87-93, 2007. 